\title{
The risk factors of heart failure in elderly patients with hip fracture: what should we care
}

Fei You ${ }^{*}$, Chaoyang Ma ${ }^{\dagger}$, Fangfang Sun ${ }^{*}$, Lian Liu and Xiuwen Zhong

\begin{abstract}
Background: Heart failure is a common adverse postoperative complication in elderly patients. It is necessary to explore the risk factors of heart after the operation of elderly patients with hip fracture during hospitalization.

Methods: Patients with hip fractures admitted to our hospital from January 1, 2019 to December 312020 were included, all the patients received internal fixation surgery. The characteristics of patients with and without postoperative heart failure were compared. Multivariate logistic regression analyses were applied to analyze the risk factors of heart failure in elderly patients with hip fracture.

Results: A total of 283 patients with hip fractures were included, the incidence of heart failure was $12.37 \%$. There were significant differences in the age, hypertension, anemia hypoalbuminemia and duration of surgery between heart failure and no heart failure group(all $p<0.05$ ). There were no significant differences in the gender, BMI, diabetes mellitus, hyperlipidemia, history of heart failure, cognitive dysfunction, type of fracture, preoperative oxygen saturation, white blood cell count, platelet count, red blood cell count, creatinine, alanine aminotransferase, aspartate aminotransferase and estimated blood loss during surgery between heart failure and no heart failure group(all $p>0.05)$. Logistic regression analyses indicated that age $\geq 70 y(O R 2.446,95 \% \mathrm{Cl} 1.044 \sim 4.149)$, hypertension(OR2.152, 95\% Cl1.125 4.023), anemia(OR3.094, 95\% Cl1.294 5.907), hypoalbuminemia(OR2.377, 95\% Cl1.205 4.537), duration of surgery $\geq 120 \mathrm{~min}(\mathrm{OR} 1.683,95 \% \mathrm{Cl} 1.094 \sim 2.782)$ were the risk factors of heart failure in elderly patients with hip fracture(all $p<0.05)$.

Conclusions: The incidence of postoperative heart failure in elderly patients with hip fracture is relatively high, which is the result of a combination of high-risk factors. Peri-period risk assessment and prevention of related risks are the keys to a good prognosis for patients.
\end{abstract}

Keywords: Heart failure, Elderly, Hip fracture, Care, Management

\footnotetext{
* Correspondence: youfei03@yeah.net; youfei03@yeah.net

${ }^{\dagger}$ Fei You and Chaoyang Ma contributed equally to this manuscript.

Department of Rehabilitation Medicine, Tongji Medical College, The Central Hospital of Wuhan, Huazhong University of Science and Technology, No.26

Shengli Street, Jiang'an District, Wuhan City, Hubei Province, China
}

(c) The Author(s). 2021 Open Access This article is licensed under a Creative Commons Attribution 4.0 International License, which permits use, sharing, adaptation, distribution and reproduction in any medium or format, as long as you give appropriate credit to the original author(s) and the source, provide a link to the Creative Commons licence, and indicate if changes were made. The images or other third party material in this article are included in the article's Creative Commons licence, unless indicated otherwise in a credit line to the material. If material is not included in the article's Creative Commons licence and your intended use is not permitted by statutory regulation or exceeds the permitted use, you will need to obtain permission directly from the copyright holder. To view a copy of this licence, visit http://creativecommons.org/licenses/by/4.0/ The Creative Commons Public Domain Dedication waiver (http://creativecommons.org/publicdomain/zero/1.0/) applies to the data made available in this article, unless otherwise stated in a credit line to the data. 


\section{Background}

Hip fracture is a common type of fracture in the elderly. It mainly refers to fractures of the proximal femur, including femoral neck fractures, intertrochanteric fractures and subtrochanteric fractures [1]. Femoral neck fractures and intertrochanteric fractures account for $90 \%$ of hip fractures [2]. As the number of elderly people grows, by 2040, the number of hip fractures in the China will exceed 500,000 each year [3]. In general, the incidence of hip fractures increases with the age of patients [4]. Studies [5, 6] have found that the incidence of hip fractures in people older than 85 years is $10-15$ times that of people aged 60-65. Due to the function decline of various organs in the body combined with other diseases and the influence of various complications in the elderly, the mortality after hip fracture is very high [7]. A large number of studies [8-10] have confirmed that compared with the population without fracture, patients with hip fracture have a significantly increased risk of death of $1.46 \sim 3.06$ times. The high incidence of hip fractures in the elderly and the physiological characteristics of the elderly, and the presence of comorbidities and pathological conditions, specially geriatric syndromes, make the treatment of hip fractures in this specific population a major challenge for clinical orthopedic physicians $[9,11]$.

Studies $[12,13]$ have found that the occurrence of heart failure in elderly patients with hip fractures is common and serious. Heart failure after surgery can lead to delayed recovery, longer hospital stays, increased medical costs, and other complications such as bedsores, fall fractures, etc., which seriously affect the patient's physical function and quality of life $[14,15]$. Analyzing the exact high-risk factors that lead to postoperative heart failure is an effective way to clarify the mechanism, and can provide a theoretical basis for the prevention and treatment of postoperative heart failure. Therefore, this study aims to analyze the risk factors of heart failure after hip fracture in the elderly, to identify the potential influencing factors and possible mechanisms, and to provide a basis for the prevention and treatment of heart failure after surgery.

\section{Methods}

\section{Ethics}

This study was a retrospective cohort study. In this study, all methods were performed in accordance with the relevant guidelines and regulations. This present study was approved by the ethics committee of The Central Hospital of Wuhan(approval number: AC201802115), and informed consents had been obtained from all the included patients.

\section{Patients}

We selected patients with hip fractures admitted to our hospital from January 1, 2019 to December 31, 2020, as the research objects. The inclusion criteria of the patients in this study were: age $\geq 60$ years old; the patients had been diagnosed as hip fracture with no other fractures; patients received internal fixation surgery in our hospital; the patients were informed and willing to join this study. Exclusion criteria were: patients with incomplete clinical data; patients with heart failure before the surgery; patients with pathological fractures or advanced tumors; Patients with pulmonary embolism before surgery; Patients who were not willing to participate in this study.

\section{Heart failure diagnosis}

Heart failure was diagnosed according to the "Guidelines for the Diagnosis and Treatment of Acute Heart Failure" formulated by the Cardiovascular Branch of the Chinese Medical Association, the heart failure was diagnosed based on clinical manifestations and auxiliary examinations [16]: The left ventricular ejection fraction (LVEF) decreased by $<45 \%$; there were signs of tachycardia, shortness of breath, lungs, pleural effusion, increased jugular vein pressure, peripheral edema, liver enlargement, heart chamber enlargement, third heart sound, heart murmur, abnormal echocardiogram, elevated levels of natriuretic peptide. We monitored the occurrence of heart failure after the operation immediately to the discharge of patients.

\section{Data collection}

The two authors used a unified form to collect the patient's personal characteristics and related treatment information, including age, body mass index (BMI), hypertension, diabetes mellitus, hyperlipidemia, history of heart failure, anemia, hypoalbuminemia, cognitive dysfunction, type of fracture, preoperative oxygen saturation, preoperative laboratory examination including white blood cell count, platelet count, red blood cell count, creatinine, alanine aminotransferase, aspartate aminotransferase, duration of surgery, estimated blood loss during surgery, methods of anesthesia including lumbar anesthesia and general anesthesia, estimated blood loss during surgery(blood loss $=$ (weight of blood gauze-weight of dry gauze) + blood volume in suction bottle). Besides, we collected hemodynamic parameters during the surgery, including the average heart rate difference $(\triangle \mathrm{HR})$, systolic blood pressure difference $(\triangle \mathrm{SBP})$, diastolic pressure difference $(\triangle \mathrm{DBP})$, perfusion index $(\mathrm{PI})$ difference $(\triangle \mathrm{PI})$, pulse oxygen perfusion variation index (PVI) difference $(\Delta \mathrm{PVI})$.

\section{Statistical Analysis}

In this study, SPSS 25.0 software was used for statistical analysis. Measurement data were expressed as mean \pm standard deviation, two independent sample t-tests were 
used for comparison between groups, count data were displayed as rates or percentages, and chi-square test was used for comparison between groups. Multivariate logistic regression model was used to analyze the risk factors of heart failure in elderly patients with hip fracture during hospitalization. In this study, $\mathrm{P}<0.05$ was regarded as the difference with statistical significance.

\section{Results}

\section{The characteristics of included patients}

A total of 283 patients with hip fractures were included in this present study, of whom 35 patietns had heart failure after surgery, the incidence of heart failure in elder patients with hip fracture was
$12.37 \%$. As presented in Table 1 , there were significant differences in the age, hypertension, anemia hypoalbuminemia and duration of surgery between heart failure and no heart failure group (all $p<0.05)$, and there were no significant differences in the gender, BMI, diabetes mellitus, hyperlipidemia, history of heart failure, cognitive dysfunction, type of fracture, preoperative oxygen saturation, white blood cell count, platelet count, red blood cell count, creatinine, alanine aminotransferase, aspartate aminotransferase and estimated blood loss during surgery, methods of anesthesia, $\triangle \mathrm{HR}, \triangle \mathrm{SBP}, \triangle \mathrm{DBP}, \triangle \mathrm{PI}$ and $\triangle \mathrm{PVI}(\%)$ between heart failure and no heart failure group had been found(all $p>0.05$ ).

Table 1 The characteristics of included patients

\begin{tabular}{|c|c|c|c|c|}
\hline Variables & HF group $(n=35)$ & No HF group $(n=248)$ & $t / x^{2}$ & $p$ \\
\hline Male/female & $19 / 16$ & $136 / 112$ & 1.086 & 0.067 \\
\hline Age(y) & $73.15 \pm 8.92$ & $66.93 \pm 7.44$ & 1.534 & 0.044 \\
\hline BMI $\left(\mathrm{kg} / \mathrm{m}^{2}\right)$ & $22.63 \pm 3.25$ & $22.23 \pm 2.09$ & 4.131 & 0.071 \\
\hline Hypertension & $25(71.43 \%)$ & $72(29.03 \%)$ & 1.094 & 0.008 \\
\hline Diabetes mellitus & $11(31.43 \%)$ & $60(24.19 \%)$ & 1.282 & 0.057 \\
\hline Hyperlipidemia & $9(25.71 \%)$ & $52(20.97 \%)$ & 1.699 & 0.102 \\
\hline History of HF & $2(5.71 \%)$ & $12(4.84 \%)$ & 1.142 & 0.114 \\
\hline Anemia & $19(54.29 \%)$ & $47(18.95 \%)$ & 1.422 & 0.036 \\
\hline Hypoalbuminemia & $10(28.57 \%)$ & $34(13.71 \%)$ & 1.062 & 0.016 \\
\hline Cognitive dysfunction & $3(8.57 \%)$ & $19(7.66 \%)$ & 0.966 & 0.087 \\
\hline Type of fracture & & & 1.214 & 0.073 \\
\hline Intertrochanteric fracture & $16(45.71 \%)$ & $110(44.35 \%)$ & & \\
\hline Femoral neck fracture & $19(54.29 \%)$ & $138(55.65 \%)$ & & \\
\hline Preoperative oxygen saturation(\%) & $94.64 \pm 10.31$ & $95.75 \pm 10.09$ & 9.347 & 0.081 \\
\hline \multicolumn{5}{|l|}{ Preoperative laboratory examination } \\
\hline White blood cell count $\left(\times 10^{9} \cdot \mathrm{L}^{-1}\right)$ & $9.03 \pm 1.61$ & $8.93 \pm 1.23$ & 1.128 & 0.077 \\
\hline Platelet count $\left(\times 10^{9} \cdot \mathrm{L}^{-1}\right)$ & $213.71 \pm 84.52$ & $210.24 \pm 123.12$ & 1.246 & 0.104 \\
\hline Red blood cell count $\left(\times 10^{9} \cdot \mathrm{L}^{-1}\right)$ & $4.73 \pm 1.17$ & $4.66 \pm 1.14$ & 1.093 & 0.071 \\
\hline Creatinine $\left(\mu \mathrm{mol} \cdot \mathrm{L}^{-1}\right)$ & $34.13 \pm 14.36$ & $33.26 \pm 15.23$ & 2.146 & 0.085 \\
\hline Alanine aminotransferase $\left(U \cdot L^{-1}\right)$ & $18.27 \pm 10.12$ & $17.13 \pm 12.56$ & 3.108 & 0.063 \\
\hline Aspartate aminotransferase $\left(U \cdot L^{-1}\right)$ & $19.34 \pm 12.32$ & $19.46 \pm 15.30$ & 2.997 & 0.102 \\
\hline Duration of surgery(min) & $146.52 \pm 66.49$ & $112.59 \pm 75.17$ & 12.413 & 0.005 \\
\hline Methods of anesthesia & & & 2.498 & 0.113 \\
\hline lumbar anesthesia & $14(40.00 \%)$ & $105(42.34 \%)$ & & \\
\hline General anesthesia & $21(60.00 \%)$ & $143(57.66 \%)$ & & \\
\hline Estimated blood loss during surgery(ml) & $266.38 \pm 44.52$ & $260.14 \pm 40.41$ & 21.104 & 0.062 \\
\hline$\Delta \mathrm{HR}(/ \mathrm{min})$ & $14.49 \pm 3.12$ & $15.18 \pm 3.52$ & 1.072 & 0.065 \\
\hline$\Delta \mathrm{SBP}(\mathrm{mmHg})$ & $17.62 \pm 2.83$ & $29.69 \pm 4.55$ & 5.128 & 0.092 \\
\hline$\triangle \mathrm{DBP}(\mathrm{mmHg})$ & $16.17 \pm 2.24$ & $15.52 \pm 3.17$ & 1.206 & 0.085 \\
\hline$\Delta \mathrm{Pl}(\%)$ & $3.18 \pm 1.41$ & $3.34 \pm 1.28$ & 1.299 & 0.106 \\
\hline$\Delta \mathrm{PVI}(\%)$ & $3.96 \pm 1.02$ & $4.12 \pm 1.21$ & 1.384 & 0.059 \\
\hline
\end{tabular}




\section{The risk factors of heart failure in elderly patients with hip fracture}

We included the factors with significant difference in the univariate analysis for further multivariate logistic regression. The variable assignments of multivariate logistic regression were indicated in Table 2. As presented in Table 3, logistic regression analyses had found that age $\geq 70 y(O R 2.446,95 \%$ CI1.044 4.149), hypertension(OR2.152, 95\% CI1.125 4.023), anemia(OR3.094, 95\% CI1.294 5.907), hypoalbuminemia(OR2.377, 95\% CI1.205 4.537), duration of surgery $\geq 120 \min ($ OR1.683, $95 \%$ CI1.094 2.782) were the risk factors of heart failure in elderly patients with hip fracture(all $p<0.05)$.

\section{Discussion}

With the aging of the population and the development of modern medicine, the treatment mode of hip fracture has gradually evolved from "fracture" as the center to "elderly patients" as the center [17]. The organ function of elderly patients is gradually deteriorating. On the basis of chronic systemic diseases, the risks of surgery are naturally increased. Therefore, special attention should be paid to the perioperative management of elderly patients [18]. The aging of the population is a common challenge facing the world. Cardiovascular disease is the most common concomitant disease for elderly patients [19, 20]. Cardiovascular disease is closely related to cerebrovascular disease, diabetes, and kidney disease [21]. Hip fractures tend to occur in the elderly, and are often accompanied by various chronic diseases, poor organ compensatory function [22]. Several previous studies [23-25] have reported that hip fractures are closely associated with geriatric syndromes such as falls, frailty, sarcopenia, polypharmacy and degenerative neurological disorders. The surgical methods including hip replacement or internal fixation depend and are determined by the kind of fracture, and that trochanteric fractures are the most frequent fractures as the patient ages. Surgical treatment is the first choice, but the operation itself is also a kind of trauma, which may aggravate various existing medical complications, and the clinical symptoms of elderly patients with heart failure are not typical [26, 27]. The results of this study show that the incidence of

Table 2 The variable assignment of multivariate logistic regression

\begin{tabular}{lll}
\hline Factors & Variables & Assignment \\
\hline HF & $Y$ & Yes $=1, \mathrm{no}=2$ \\
Age(y) & $X_{1}$ & $\geq 70=1,<70=2$ \\
Hypertension & $X_{2}$ & Yes $=1, \mathrm{no}=2$ \\
Anemia & $X_{3}$ & Yes $=1, \mathrm{no}=2$ \\
Hypoalbuminemia & $X_{4}$ & Yes $=1, \mathrm{no}=2$ \\
Duration of surgery(min) & $X_{5}$ & $\geq 120=1,<120=2$ \\
\hline
\end{tabular}

postoperative heart failure in patients with hip fractures is relatively high, we have found that age $\geq 70 y$, hypertension, anemia, hypoalbuminemia, duration of surgery $\geq$ $120 \mathrm{~min}$ are the risk factors of heart failure in elderly patients with hip fracture. In clinical practice, medical staff should take early intervention for these risk factors to reduce the risk of postoperative complications.

Common surgical methods for hip fractures are hip joint replacement and internal fixation. Among them, hip replacement has the characteristics of large surgical trauma, longer operation time and high blood loss, and may also involve many problems such as bone cement implantation, while hip internal fixation has the advantages of relatively minimal invasiveness, short operation time and no bone cement implantation $[28,29]$. In this study, only the impact of the difference between hip extramedullary fixation and intramedullary fixation on postoperative cardiovascular complications in elderly patients with hip fractures was discussed, and patients who underwent hip replacement were not included, which may weaken the influences of surgical approach [30]. A large number of studies [31-33] have focused on the cardiovascular events in patients undergone hip replacement, but very few focused on the patients undergone fixation treatment, our study findings, to some extent fill this gap.

Previous studies $[34,35]$ have shown that patients aged $\geq 70$ years have a $7.9 \%$ incidence of cardiovascular complications after knee arthroplasty. Therefore, for elderly patients, more detailed examination and evaluation should be performed before surgery. Anesthesiology consultation, optimization of internal medicine, attention to anesthesia management during the operation, reduction of surgical trauma and operation time, strict monitoring and multidisciplinary perioperative management after surgery $[8,36]$. At the same time, it is also noted that even patients under 60 years of age, there will be serious cardiovascular complications after artificial joint replacement, the incidence of which is $2.7 \% \%$ [37]. For these non-high-risk patients, preoperative conversations should also explain the risk of cardiovascular events, and preoperative examination and perioperative management should not be ignored [38, 39].

Studies $[40,41]$ have shown that anemia is closely related to the prognosis of hip fractures. Studies have found that the mortality of patients with anemia at 3 and 12 months after discharge from the hospital is significantly higher than that of patients without anemia. At the same time, studies [42, 43] have shown that the mortality of patients with anemia has increased significantly. Anemia at admission for elderly patients with hip fractures is an independent risk factor for respiratory complications and fever, and an independent risk factor for postoperative complications in female patients [44]. 
Table 3 Logistic regression analysis on the risk factors of HF in elderly patients with hip fracture

\begin{tabular}{llllll}
\hline Variables & $\boldsymbol{\beta}$ & $\mathbf{S}^{-} \mathbf{x}$ & OR & $\mathbf{9 5 \%} \mathbf{C l}$ & $\mathbf{p}$ \\
\hline Age $\geq 70 y$ & 0.102 & 0.218 & 2.446 & $1.044 \sim 4.149$ & 0.012 \\
Hypertension & 0.179 & 0.120 & 2.152 & $1.125 \sim 4.023$ & 0.015 \\
Anemia & 0.132 & 0.137 & 3.094 & $1.294 \sim 5.907$ & 0.036 \\
Hypoalbuminemia & 0.141 & 0.112 & 2.377 & $1.205 \sim 4.537$ & 0.023 \\
Duration of surgery $\geq 120 \mathrm{~min}$ & 0.129 & 0.105 & 1.683 & $1.094 \sim 2.782$ \\
\hline
\end{tabular}

This study also confirmed that anemia is an independent risk factor for postoperative heart failure. The possible mechanism is that the reduction of hemoglobin level can reduce the total amount of oxygen carried by red blood cells, and the hypoxia of body tissues promotes the release of nitric oxide, which leads to peripheral vasodilatation and decreased peripheral resistance, thereby activating the adrenal sympathetic nervous system and renin-angiotensin $[45,46]$. The aldosterone system promotes the secretion of antidiuretic hormones, leading to water and sodium retention, which aggravates the symptoms of heart failure to a certain extent $[47,48]$.

The relationship between the length of surgery and postoperative heart failure is worth considering. This study found that the longer the operation time, the greater the risk of heart failure. It may be explained that the longer the operation time, the longer the patient's stress time, resulting in greater stress on the heart [49]. In addition, patients often receive a certain amount of fluid infusion during surgery, the longer the duration of surgery, the more fluid will be infused, and the patient's heart load will increase significantly [50]. The duration of hip fracture surgery is relatively long, and there are also certain differences in the duration of different surgical methods and materials [51, 52]. Therefore, clinical medical workers should focus on the appropriate surgical materials and methods before surgery, and at the same time strengthen the doctor's surgical skills, shorten the operation time as much as possible, so as to reduce the incidence of heart failure in patients after the operation.

This study has the several shortcomings that must be concerned. Firstly, this study did not include patients with hip replacement, these patients are more prone to fluctuations in hemodynamics during the perioperative period, and the occurrence of postoperative cardiovascular events have been discussed in many previous published studies. We focused on patients undergoing internal fixation after hip fracture. Secondly, this study is a retrospective study. It lacks intraoperative hemodynamic indicators, postoperative pain treatment, and evaluation of patient subjective indicators, which remains to be further analyzed and discussed in follow-up studies. Besides, sodium retention is not only related to hypoaldosteronism stages in the elderly, but it is a more complex entity that involves physiological and pathological conditions, such as changes in body composition, ADH hypothalamic thresholds, inadequate pain control and other pathologies that leads to a syndrome of inappropriate secretion of antidiuretic hormone. Water and sodium retention is a vital factor that should be considered in the management of heart failure, we tried to collected more data about the water and sodium retention such as the fluid intake and serum sodium level to evaluate the associations of heart failure, but the relevant data were not complete. Thirdly, when hip fractures are clearly more related to female sex when we talk of frailty fractures among elderly population, yet our study had included more male patients than female patients, which might be associated with the population and area differences, and we only included two-years data in a single hospital. Future studies with larger sample size and multi-sites are needed.

\section{Conclusions}

In conclusions, the postoperative heart failure is a common and serious complications for elder patients with hip fracture. The occurrence of postoperative heart failure of elderly hip fractures is the result of a combination of many factors, age $\geq 70 y$, hypertension, anemia, hypoalbuminemia, duration of surgery $\geq 120$ min are the risk factors of heart failure in elderly patients with hip fracture. Early monitoring and correcting hypertension, anemia and hypoalbuminemia before surgery, shortening the duration of surgery are needed in clinical practice to reduce the occurrence of postoperative heart failure. Correct prediction and evaluation help patients to tide over the difficulties of surgery smoothly, minimize the risk of surgery, and enable patients to achieve the greatest degree of recovery.

\section{Abbreviations \\ BMl: Body mass index}

\section{Acknowledgements \\ None.}

\section{Authors' contributions}

F Y, C M designed research; F Y, C M, F S, L L, X Z conducted research; F Y analyzed data; F Y, F S wrote the first draft of manuscript; F Y had primary responsibility for final content. All authors read and approved the final manuscript. 
Funding

None.

\section{Availability of data and materials}

All data generated or analyzed during this study are included in this published article.

\section{Declarations}

\section{Ethics approval and consent to participate}

This study was a retrospective cohort study. In this study, all methods were performed in accordance with the relevant guidelines and regulations. This present study was approved by the ethics committee of the Central Hospital of Wuhan(approval number: AC201802115), and informed consents had been obtained from all the included patients.

\section{Consent for publication}

Not applicable.

\section{Competing interests}

The authors declare that they have no competing interests.

Received: 27 March 2021 Accepted: 27 August 2021

Published online: 28 September 2021

\section{References}

1. Veronese N, Maggi S. Epidemiology and social costs of hip fracture. Injury. 2018;49(8):1458-60.

2. Kim BS, Lim JY, Ha YC. Recent Epidemiology of Hip Fractures in South Korea. Hip Pelvis. 2020;32(3):119-24.

3. Yu F, Xia W. The epidemiology of osteoporosis, associated fragility fractures, and management gap in China. Arch Osteoporos. 2019;14(1):32.

4. Dhanwal DK, Dennison EM, Harvey NC, Cooper C. Epidemiology of hip fracture: Worldwide geographic variation. Indian J Orthop. 2011:45(1):15-22.

5. Diaz-Ledezma C, Bengoa F, Dabed D, Rojas N, Lopez A. Hip fractures in the elderly Chilean population: a projection for 2030. Arch Osteoporos. 2020; 15(1):116.

6. Wong KC, Cheok JWG, Tay KXK, Koh SB, Howe TS. Where have all the hip fractures gone? Osteoporos Int. 2020;31(10):2057-8.

7. Lin TC, Wang PW, Lin CT, Chang YJ, Lin YJ, Liang WM, Lin JC. Primary hemiarthroplasty after unstable trochanteric fracture in elderly patients: mortality, readmission and reoperation. BMC Musculoskelet Disord. 2021; 22(1):403.

8. Guzon-Illescas O, Perez Fernandez E, Crespi Villarias N, Quiros Donate FJ, Pena M, Alonso-Blas C, Garcia-Vadillo A, Mazzucchelli R. Mortality after osteoporotic hip fracture: incidence, trends, and associated factors. J Orthop Surg Res. 2019:14(1):203.

9. Lim MA, Pranata R. Coronavirus disease 2019 (COVID-19) markedly increased mortality in patients with hip fracture - A systematic review and metaanalysis. J Clin Orthop Trauma. 2021;12(1):187-93.

10. Brown JP, Adachi JD, Schemitsch E, Tarride JE, Brown V, Bell A, Reiner M, Oliveira T, Motsepe-Ditshego P, Burke N, et al. Mortality in older adults following a fragility fracture: real-world retrospective matched-cohort study in Ontario. BMC Musculoskelet Disord. 2021;22(1):105

11. Malik AT, Alexander JH, Khan SN, Scharschmidt TJ. Where Will Pathologic Hip Fractures Go in a Value-based Hip Fracture Bundle? J Am Acad Orthop Surg. 2020;28(22):e995-1000.

12. Lesnyak O, Ismailov S, Shakirova M, Alikhanova N, Zakroyeva A, Abboskhujaeva L, Johansson H, Harvey NC, McCloskey E, Kanis JA. Epidemiology of hip fracture and the development of a FRAX model for Uzbekistan. Arch Osteoporos. 2020;15(1):119.

13. Imamura T. The prognostic impact of heart failure with preserved ejection fraction in elderly patients with hip fracture. Injury. 2020;51(4):1132.

14. Ponschab M, Hochmair N, Ghazwinian N, Mueller T, Plochl W. Levosimendan infusion improves haemodynamics in elderly heart failure patients undergoing urgent hip fracture repair. Eur J Anaesthesiol. 2008; 25(8):627-33.

15. Cha YH, Ha YC, Ryu HJ, Lee YK, Park SH, Lee KJ, Koo KH. Effect of heart failure on postoperative short and long-term mortality in elderly patients with hip fracture. Injury. 2020;51(3):694-8.
16. Diseases CSoC, Association CM, Diseases, EBoCJoC. Guidelines for the diagnosis and treatment of acute heart failure. Chinese Journal of Cardiovascular Diseases. 2010;38(3):195-208.

17. Alexiou Kl, Roushias A, Varitimidis SE, Malizos KN. Quality of life and psychological consequences in elderly patients after a hip fracture: a review. Clin Interv Aging. 2018;13:143-50.

18. Amarilla-Donoso FJ, Lopez-Espuela F, Roncero-Martin R, Leal-Hernandez O, Puerto-Parejo LM, Aliaga-Vera I, Toribio-Felipe R, Lavado-Garcia JM. Quality of life in elderly people after a hip fracture: a prospective study. Health Qual Life Outcomes. 2020;18(1):71.

19. Chen FP, Fu TS, Lin YC, Fan CM. Risk factors and quality of life for the occurrence of hip fracture in postmenopausal women. Biomed J. 2018;41(3): 202-8.

20. Wahlsten LR, Zareini B, Smedegaard L, Gislason GH, Palm H, Brorson S: A medical history of arterial thrombosis is a strong predictor of post-operative myocardial infarction and stroke in patients with hip fractures-a nationwide cohort study. Age Ageing 2021

21. Dyer SM, Crotty M, Fairhall N, Magaziner J, Beaupre LA, Cameron ID, Sherrington C. Fragility Fracture Network Rehabilitation Research Special Interest G: A critical review of the long-term disability outcomes following hip fracture. BMC Geriatr. 2016:16:158.

22. Sim YE, Sim SD, Seng C, Howe TS, Koh SB, Abdullah HR. Preoperative Anemia, Functional Outcomes, and Quality of Life After Hip Fracture Surgery. J Am Geriatr Soc. 2018;66(8):1524-31.

23. Clement ND, van der Linden M, Keating JF. Higher rate of complications with uncemented compared to cemented total hip arthroplasty for displaced intracapsular hip fractures: A randomised controlled trial of 50 patients. Eur J Orthop Surg Traumatol. 2021;31(3):587-94.

24. Ingstad F, Solberg LB, Nordsletten L, Thorsby PM, Hestnes I, Frihagen F. Vitamin D status and complications, readmissions, and mortality after hip fracture. Osteoporos Int. 2021;32(5):873-81.

25. Broggi MS, Oladeji PO, Tahmid S, Hernandez-Irizarry R, Allen J. Depressive Disorders Lead to Increased Complications After Geriatric Hip Fractures. Geriatr Orthop Surg Rehabil. 2021;12:21514593211016252.

26. Koh DTS, Chen JY, Yew AKS, Chong HC, Hao Y, Pang HN, Tay DKJ, Chia SL, Lo NN, Yeo SJ. Functional outcome and quality of life in patients with hip fracture after total knee arthroplasty. J Orthop Surg (Hong Kong). 2019;27(2): 2309499019852338

27. AbuSharar SP, Bess L, Hennrikus E. Pre-operative echocardiograms in acute fragility hip fractures: How effective are the guidelines? Medicine (Baltimore). 2021;100(12):e25151.

28. Wu JQ, Mao LB, Wu J. Efficacy of balance training for hip fracture patients: a meta-analysis of randomized controlled trials. J Orthop Surg Res. 2019;14(1):83.

29. Szulc P, Foesser D, Chapurlat R: High Cardiovascular Risk in Older Men with Poor Bone Microarchitecture-The Prospective STRAMBO Study. J Bone Miner Res 2021.

30. Prieto-Alhambra D, Moral-Cuesta D, Palmer A, Aguado-Maestro I, Bardaji MFB, Branas F, Bueno GA, Caeiro-Rey JR, Cano IA, Barres-Carsi M, et al. The impact of hip fracture on health-related quality of life and activities of daily living: the SPARE-HIP prospective cohort study. Arch Osteoporos. 2019;14(1):56

31. Tedesco D, Gibertoni D, Rucci P, Hernandez-Boussard T, Rosa S, Bianciardi L, Rolli M, Fantini MP. Impact of rehabilitation on mortality and readmissions after surgery for hip fracture. BMC Health Serv Res. 2018:18(1):701.

32. Guirant L, Carlos F, Curiel D, Kanis JA, Borgstrom F, Svedbom A, Clark P. Health-related quality of life during the first year after a hip fracture: results of the Mexican arm of the International Cost and Utility Related to Osteoporotic Fractures Study (MexICUROS). Osteoporos Int. 2018; 29(5):1147-54.

33. Wantonoro W, Kuo WY, Shyu YL. Changes in Health-Related Quality of Life for Older Persons With Cognitive Impairment After Hip Fracture Surgery: A Systematic Review. J Nurs Res. 2020;28(3):e97.

34. de Miguel Artal M, Roca Chacon O, Martinez-Alonso M, Serrano Godoy M, Mas Atance J, Garcia Gutierrez R. [Hip fracture in the elderly patient: Prognostic factors for mortality and functional recovery at one year]. Rev Esp Geriatr Gerontol. 2018;53(5):247-54

35. Bohsali F, Klimpl D, Baumgartner R, Sieber F, Eid SM. Effect of Heart Failure With Preserved Ejection Fraction on Perioperative Outcomes in Patients Undergoing Hip Fracture Surgery. J Am Acad Orthop Surg. 2020;28(3):e131-8 
36. Tarazona-Santabalbina FJ, Ojeda-Thies C, Figueroa Rodriguez J, CassinelloOgea C, Caeiro JR: Orthogeriatric Management: Improvements in Outcomes during Hospital Admission Due to Hip Fracture. Int J Environ Res Public Health 2021, 18(6).

37. Tamamura Y, Matsuura M, Shiba S, Nishikimi T. Heart failure assessed based on plasma B-type natriuretic peptide (BNP) levels negatively impacts activity of daily living in patients with hip fracture. PLoS One. 2020;15(8):e0237387.

38. Acan AE, Ozlek B, Kilinc CY, Biteker M, Aydogan NH. Perioperative outcomes following a hip fracture surgery in elderly patients with heart failure with preserved ejection fraction and heart failure with a mid-range ejection fraction. Ulus Travma Acil Cerrahi Derg. 2020;26(4):600-6.

39. Cicek V, Cinar T, Hayiroglu MI, Kilic S, Keser N, Uzun M, Orhan AL: Preoperative cardiac risk factors associated with in-hospital mortality in elderly patients without heart failure undergoing hip fracture surgery: a single-centre study. Postgrad Med I 2020.

40. Bin W, Mao X, Liping Z. Analysis of risk factors for postoperative cardiovascular complications in elderly patients with hip fracture. Journal of Clinical Anesthesiology. 2018;34(3):222-5.

41. Cuesta-Peredo D, Arteaga-Moreno F, Belenguer-Varea A, Llopis-Calatayud JE, Sivera-Gimeno S, Santaeugenia SJ, Avellana-Zaragoza JA, TarazonaSantabalbina FJ. Influence of hospital adverse events and previous diagnoses on hospital care cost of patients with hip fracture. Arch Osteoporos. 2019;14(1):88.

42. Tiezhou W, Shanming W, Caimai W. Analysis of related risk factors for perioperative heart failure of hip fractures in the elderly. Chinese Journal of Geriatrics. 2016;35(9):978-81.

43. Brunskill SJ, Millette SL, Shokoohi A, Pulford EC, Doree C, Murphy MF, Stanworth S: Red blood cell transfusion for people undergoing hip fracture surgery. Cochrane Database Syst Rev 2015(4):CD009699.

44. Baorong Z, Zheng Y. Analysis of related factors of heart failure after hip fracture in the elderly. Chinese Journal of Multiple Organ Diseases in the Elderly. 2018;17(7):505-8.

45. Zerah L, Dourthe L, Cohen-Bittan J, Verny M, Raux M, Meziere A, Khiami F, Tourette C, Neri C, Le Manach Y, et al. Retrospective Evaluation of a Restrictive Transfusion Strategy in Older Adults with Hip Fracture. J Am Geriatr Soc. 2018;66(6):1151-7.

46. Colon-Emeric CS. Postoperative management of hip fractures: interventions associated with improved outcomes. Bonekey Rep. 2012;1:241.

47. Folbert EC, Hegeman JH, Gierveld R, van Netten JJ, Velde DV, Ten Duis HJ, Slaets JP. Complications during hospitalization and risk factors in elderly patients with hip fracture following integrated orthogeriatric treatment. Arch Orthop Trauma Surg. 2017;137(4):507-15.

48. Gogas BD, Parissis JT, Filippatos GS, lliodromitis EK, Soultanis KC, Kostopanagiotou GG, Theodoropoulos SP, Kremastinos DT, Yacoub MH. Severe anaemia and subcapital femur fracture in a patient with Left Ventricular Assist Device Heart Mate II: the cardiologist's management of this rare patient. Eur J Heart Fail. 2009;11(8):806-8.

49. Changhua L, Wenliang C, Guangmao L. Analysis of the factors of heart failure during the perioperative period of elderly femoral shaft fractures. China Orthopedics and Traumatology. 2018;31(2):150-4.

50. Wei S, Zhibin H. Risk factors for cardiovascular events and deep vein thrombosis after hip replacement. Chinese Journal of Evidence-Based Cardiovascular Medicine. 2015;14(4):490-2.

51. Tingting $\mathrm{S}$, Xinmin $\mathrm{W}$, Xile B. Analysis of risk factors for perioperative heart failure of hip fractures in the elderly. Chinese Electronic Journal of Geriatric Orthopedics and Rehabilitation. 2018;4(1):23-8.

52. Lanhuaxiang. Analysis of risk factors for perioperative heart failure in the elderly with hip fractures. Cardiovascular disease prevention and treatment knowledge. 2020;10(5):84-6.

\section{Publisher's Note}

Springer Nature remains neutral with regard to jurisdictional claims in published maps and institutional affiliations.

Ready to submit your research? Choose BMC and benefit from:

- fast, convenient online submission

- thorough peer review by experienced researchers in your field

- rapid publication on acceptance

- support for research data, including large and complex data types

- gold Open Access which fosters wider collaboration and increased citations

- maximum visibility for your research: over $100 \mathrm{M}$ website views per year

At BMC, research is always in progress.

Learn more biomedcentral.com/submissions 